\title{
Supply Chain Coordination for Strong Retailer with Extended Warranty under Network Externality
}

\author{
Yan-Fei Tan, Yu-Yin Yi, Jun-Jiang Yao \\ Management School, Jinan University, Guangzhou, China \\ Email: tanyfei@foxmail.com
}

Received 11 March 2015; accepted 22 June 2015; published 26 June 2015

Copyright $(02015$ by authors and Scientific Research Publishing Inc.

This work is licensed under the Creative Commons Attribution International License (CC BY). http://creativecommons.org/licenses/by/4.0/

\begin{abstract}
This paper constructed a retailer-leading supply chain system considering the extended warranty (EW) with single manufacturer and single retailer to study the influence of network externality on retailer-leading supply chain coordination. First of all, we analyzed and compared the retail price, EW price, EW quality, and the total system profit in centralized and decentralized model respectively. Then we analyzed the influence of network externality on decision variables and system profits. We found that the network externality increased the loss of decision efficiency. After that, we considered the coordination of the supply chain system with extended warranty. Finally, some numerical examples were presented for further analysis.
\end{abstract}

\section{Keywords}

Extended Warranty, Network Externality, Contract Coordination, Game Model, Two-Part Tariff

\section{Introduction}

In recent years, as the expansion of giant electric equipment retailers such as Gome, Suning and so forth, some retailers have more discourse power in supply chain. And changes of the dominant force in the supply chain have important impact on the node enterprises and the performance of the supply chain system. However, the intense competition makes profit of appliances retail so less that retailers start looking for new profit growth points, one of which is after-sales service. Among the after-sales services, extend warranty service by paying which is also called extended warranty, is noted widely.

Researches on extended warranty mainly discuss the rationality and the related influence factors of the extended warranty from the theoretical and empirical perspective [1] [2]. Scholars focused on the following as- 
pects: one is the design of the extended warranty, which is researched from the points of view such as cost of extended warranty [3], range of extended warranty [4], customers' risk preferences [5], period of extended warranty [6], the additive demand [7] and so forth. The second is about the selection of supply chain extended warranty mode and its optimization. Desai and Padmanabhan [8] studied the coordination of extended warranty distribution channels from manufacturers' standpoint and its research results showed that the hybrid channel was manufacturers' optimal choice. Wang and $\mathrm{Hu}$ [9] studied how attractive index of extended warranty influenced manufacturers' choice of provision modes of extended warranty in the form of modeling. In addition, Zhang et $a l$. [10] studied the effects of service level on supply chain and manufacturers' optimal choice of extended warranty sales channels.

Obviously, the papers above provide some good ideas for the related researches of extended warranty, but currently the studies are confined to the situation of manufacturers dominating the supply chain. The problem of supply chain coordination that strong retailers dominate the supply chain and provide extended warranty (such as Gome and Suning described above) is not yet considered.

In the meantime, many products, such as mobile phones, computers and so on, have the characteristics of network externality in the network economy era. And in the reality, the commodities such as mobile phones, computers with network externality are the target customers of extended warranty. Katz and Srapiro [11] defined network externality as that a single consumer's utility increases with the increase of the total number who buy the same products. Shankar and Bayus [12] summed up that the influencing factors of network externality were network scale and the intensity of network externality. And the intensity of network externality refers to the marginal effect of the network scale increasing per unit on demand. They also pointed out that the intensity of network externality depended on the factors such as customer preferences, characteristics of consumers' background, customer loyalties and so on. After their researches, scholars carried out extensive researches and they mainly focused on topics about network externality such as price making strategy [13] [14], product development strategy [15] [16], technology licensing and decisions of compatibility [17] [18], etc. Being different from traditional economy of scale, network externality performs more like economy of scale on the demand side. Network externality influences consumers' buying decisions by influencing consumers' expectations so that manufacturers and retailers must take the change of market demand caused by the change of consumers' expectations into account while making decisions. Consequently, the existence of network externality will affect the supply chain system so that the decision-making and coordination of supply chain system have new characteristics and laws.

Furthermore, the potential consumer groups of extended warranty depend on sales of product so that the influence of network externality on sales of product further affects the demand of extended warranty. And the impact of network externality on extended warranty majorly is providers' service pricing, service quality and other decision-makings. However, previous studies rarely consider the influence of network externality on the supply chain and its coordination. Yi et al. [19] studied supply chain coordination for extended warranty from the perspective of network externality and the results showed that under the influence of network externality, the improved revenue sharing contract could make supply chain system to obtain the Pareto improvement and coordinate supply chain. In conclusion, at present there is no research involving supply chain coordination for extended warranty provided by strong retailers under network externality. Therefore, this paper have built a supply chain model that strong retailers provide extended warranty under network externality and have analyzed the impact of network externality on decision-making of product pricing, extended warranty pricing and extended warranty quality and the decision-making efficiency. We also have discussed how to coordinate the supply chain dominated by strong retailers who provide extended warranty under network externality.

\section{Problem Description and Assumptions}

We consider a two-stage supply chain system composed of single manufacturer and single retailer who provide extended warranty. Retailer is a leader in the supply chain system and manufacturer is the follower. Based on the real case of the retail giants such as Gome, Suning and so on, we assume that the retailer besides selling goods, he also provides extended warranty for consumers. Consumers may choose to buy single product or purchase the combination of goods and extended warranty.

This paper introduces the following parameters: $w$ represents manufacture's wholesale price of unit good; $c$ represents manufacture's production cost of unit good; $p$ represents retailer's retail price of unit commodity; $p_{s}$ represents retailer's unit price of extended warranty; $q_{s}$ represents the quality level of extended warranty and 
the corresponding cost of extended warranty is $k q_{s}^{2} / 2, k$ represents the average cost factor of extended warranty and that is the level of control of retailer's average cost providing extended warranty; $g$ represents the unit profit of commodity, and $g=p-w ; \pi_{j}^{i}$ represents the profits of node enterprises or supply chain system, the superscript $i=C, D$ respectively represents centralized decision-making model and decentralized decisionmaking model, subscript $j=r, m$, sc respectively represents retailer, manufacturer and the supply chain system.

Assuming that consumers formed the expected market size of the product $Q^{e}$, and their expectations determine their willing to pay for the market size $f\left(Q^{e}\right)$. According to the connotation of network externality defined by Katz and Srapiro [11], we have the following retailer's linear inverse demand function considering the network externality (A similar demand function design also can be found in the papers [11] [14] [18] [19], and that demand function captured the fact that if consumers believe that high sales of the product increase their utility, then under a given price they need more products).

$$
p=a-Q+f\left(Q^{e}\right)
$$

Among them, $a$ is the market size, and $a>c$. In order to analyze it conveniently, referencing document [18], we further assume that $f\left(Q^{e}\right)=\mu Q^{e}, \mu \in(0,1)$ is the coefficient measuring the intensity of network externality. The intensity of network externality depends on factors such as consumers' personal preferences, consumers' characteristics of background, customer's loyalty and so on. In addition, under retailer's advertising and consumers' rational expectations, we have $Q^{e}=Q$. As a result, the retailer's inverse demand function is:

$$
p=a-(1-\mu) Q
$$

And then, by using the formula we have the following retailer's commodity demand function under the condition of network externality:

$$
Q=\frac{a-p}{1-\mu}
$$

Referencing documents [7] [9], the demand of extended warranty is influenced by three factors and they respectively are sales of commodity $Q$, extended warranty price $p_{s}$ and quality of extended warranty $q_{s}$. Thus, the demand function of extended warranty is as follows:

$$
Q_{s}=Q-\beta p_{s}+\gamma q_{s}
$$

Among them, $\beta$ and $\gamma$ respectively represent the sensitive coefficient of extended warranty price and the quality of extended warranty $\beta>0, \gamma>0$. By $Q \geq Q_{s}$ we know that, when $\beta p_{s}>\gamma q_{s}$, it means part of consumers who buy the product with the extended warranty, hereinafter referred to as part of the extended warranty; when $\beta p_{s}=\gamma q_{s}$, it means all consumers who buy the product with the extended warranty, hereinafter referred to as all the extended warranty.

\section{Centralized Decision-Making Model (Model $C$ )}

The retailer and manufacture fully cooperate in this pattern. They sell commodity and provide extended warranty and also jointly decide the retail price of commodity, extended warranty price and extended warranty quality.

The profit function of the supply chain system is:

$$
\begin{gathered}
\max _{p, p_{s}, q_{s}} \pi^{C}=(p-c) Q+p_{s} Q_{s}-\frac{1}{2} k q_{s}^{2} \\
\text { s.t } \beta p_{s} \geq \gamma q_{s}
\end{gathered}
$$

By constructing the Lagrange function, we will solve the above optimal value problem with inequality constraints. The function is as follows:

$$
L_{s c}^{C}=(p-c)\left(\frac{a-p}{1-\mu}\right)+p_{s}\left(\frac{a-p}{1-\mu}-\beta p_{s}+\gamma q_{s}\right)-\frac{1}{2} k q_{s}^{2}+\lambda\left(\beta p_{s}-\gamma q_{s}\right)
$$

The optimal strategy of supply chain system needs to meet the following: 


$$
\begin{aligned}
& \frac{\partial L_{s c}^{C}}{\partial p}=\frac{a+c-2 p-p_{s}}{1-\mu}=0 ; \frac{\partial L_{s c}^{C}}{\partial p_{s}}=\frac{a-p}{1-\mu}-2 \beta p_{s}+\gamma q_{s}+\lambda \beta=0 ; \\
& \frac{\partial L_{s c}^{C}}{\partial q_{s}}=\gamma p_{s}-k q_{s}-\gamma \lambda=0 ; \lambda\left(\beta p_{s}-\gamma q_{s}\right)=0 ; \lambda \geq 0 ; \beta p_{s} \geq \gamma q_{s}
\end{aligned}
$$

(1) When $\lambda=0, \beta p_{s}>\gamma q_{s}$, that's part of extended warranty. In order to judge the sufficient condition of the existence of the optimal solution, we construct the corresponding Hesse matrix:

$$
A=\left(\begin{array}{ccc}
\frac{\partial^{2} L}{\partial p^{2}} & \frac{\partial^{2} L}{\partial p \partial p_{s}} & \frac{\partial^{2} L}{\partial p \partial q_{s}} \\
\frac{\partial^{2} L}{\partial p_{s} \partial p} & \frac{\partial^{2} L}{\partial p_{s}^{2}} & \frac{\partial^{2} L}{\partial p_{s} \partial q_{s}} \\
\frac{\partial^{2} L}{\partial q_{s} \partial p} & \frac{\partial^{2} L}{\partial q_{s} \partial p_{s}} & \frac{\partial^{2} L}{\partial q_{s}^{2}}
\end{array}\right)=\left(\begin{array}{ccc}
-\frac{2}{1-\mu} & -\frac{1}{1-\mu} & 0 \\
-\frac{1}{1-\mu} & -2 \beta & \gamma \\
0 & \gamma & -k
\end{array}\right)
$$

If and only if order principal minor determinant $A_{1}=-\frac{2}{1-\mu}<0, A_{2}=\frac{4 \beta(1-\mu)-1}{(1-\mu)^{2}}>0$, $A_{3}=-\frac{2\left(2 k \beta-\gamma^{2}\right)(1-\mu)-k}{(1-\mu)^{2}}<-\frac{\left(2 k \beta-\gamma^{2}\right)(1-\mu)-k}{(1-\mu)^{2}}<0$ hold, the optimal solution exists. It's easy to know that when $0<\mu<1-\frac{1}{4 \beta}, A_{2}>0$; when $0<\mu<1-\frac{k}{2 k \beta-\gamma^{2}}, \quad A_{3}<0$ hold. Moreover, when $\beta>1$, $\gamma^{2}<k \beta$, we have $0<1-\frac{k}{2 k \beta-\gamma^{2}}<1-\frac{1}{4 \beta}$. Therefore, the following condition (I): when $\beta>1, \gamma^{2}<k \beta$, $0<\mu<1-\frac{k}{2 k \beta-\gamma^{2}}$ hold, then $A_{1}<0, A_{2}>0, A_{3}<0$ hold, the optimal solution exists.

The corresponding optimal strategy of the supply chain system is:

$$
p^{C}=\frac{(a+c)\left(2 k \beta-\gamma^{2}\right)(1-\mu)-a k}{2\left(2 k \beta-\gamma^{2}\right)(1-\mu)-k} ; p_{s}^{C}=\frac{(a-c) k}{2\left(2 k \beta-\gamma^{2}\right)(1-\mu)-k} ; q_{s}^{C}=\frac{(a-c) \gamma}{2\left(2 k \beta-\gamma^{2}\right)(1-\mu)-k}
$$

(2) When $\lambda \neq 0, \beta p_{s}=\gamma q_{s}$, that is all the extended warranty. We order $q_{s}=\beta p_{s} / \gamma$, and substitute it into Equation (1). Then we have:

$$
L_{s c}^{C}=(p-c)\left(\frac{a-p}{1-\mu}\right)+p_{s}\left(\frac{a-p}{1-\mu}\right)-\frac{1}{2} k\left(\frac{\beta}{\gamma} p_{s}\right)^{2}
$$

In order to judge the sufficient condition of the existence of the optimal solution, we construct the corresponding Hesse matrix: $A=\left(\begin{array}{cc}\frac{\partial^{2} L}{\partial p \partial p} & \frac{\partial^{2} L}{\partial p \partial p_{s}} \\ \frac{\partial^{2} L}{\partial p_{s} \partial p} & \frac{\partial^{2} L}{\partial p_{s} \partial p_{s}}\end{array}\right)=\left(\begin{array}{cc}-\frac{2}{1-\mu} & -\frac{1}{1-\mu} \\ -\frac{1}{1-\mu} & -\frac{k \beta^{2}}{\gamma^{2}}\end{array}\right)$. If and only if order principal minor determinant $A_{1}=-\frac{2}{1-\mu}<0, A_{2}=\frac{2 k \beta^{2}(1-\mu)-\gamma^{2}}{\gamma^{2}(1-\mu)^{2}}>\frac{k \beta^{2}(1-\mu)-\gamma^{2}}{\gamma^{2}(1-\mu)^{2}}>0$ hold, the optimal solution exists. It's easy to know that when the following condition (II): $\beta>1, k \beta<\gamma^{2}<k \beta^{2}, 0<\mu<1-\frac{\gamma^{2}}{k \beta^{2}}$ hold, $A_{1}<0$, $A_{2}>0$ hold, the optimal solution exists. 
Using the same method, we can attain that under the conditions (I) and (II) in this paper, all models have the optimal solutions. It is not stated anymore due to limited space.

The corresponding optimal strategy of the supply chain system is as the following:

$$
p^{C}=\frac{(a+c) k \beta^{2}(1-\mu)-a \gamma^{2}}{2 k \beta^{2}(1-\mu)-\gamma^{2}} ; p_{s}^{C}=\frac{(a-c) \gamma^{2}}{2 k \beta^{2}(1-\mu)-\gamma^{2}} ; q_{s}^{C}=\frac{(a-c) \beta \gamma}{2 k \beta^{2}(1-\mu)-\gamma^{2}}
$$

Furthermore, as we have shown in Table 1, we can obtain the values of sales of commodity, the sales of extended warranty, profits of node enterprises and total profit of the system.

\section{Non-Cooperative-Decentralized Decision-Making Model (Model D)}

In this pattern, the retailer firstly decides the retail price of the commodity, extended warranty price and extended warranty quality. Then the manufacturer decides the wholesale price.

The manufacturer's profit function is as the following:

$$
\max _{w} \pi_{m}^{D}=(w-c) Q=(w-c) \frac{a-p}{1-\mu}
$$

The retailer's profit function is as the following:

$$
\begin{gathered}
\max _{p, p_{s}, q_{s}} \pi_{r}^{D}=(p-w) Q+p_{s} Q_{s}-\frac{1}{2} k q_{s}^{2} \\
\text { s.t } \beta p_{s} \geq \gamma q_{s}
\end{gathered}
$$

\begin{tabular}{|c|c|c|c|c|}
\hline & $\beta>1, \quad \gamma^{2}$ & $\begin{array}{l}\text { f extended warranty: } \\
k \beta, \quad 0<\mu<1-\frac{k}{2 k \beta-\gamma^{2}}\end{array}$ & \multicolumn{2}{|c|}{$\begin{array}{c}\text { All of extended warranty: } \\
\beta>1, \quad k \beta<\gamma^{2}<k \beta^{2}, 0<\mu<1-\frac{\gamma^{2}}{k \beta^{2}}\end{array}$} \\
\hline & C Model & D Model & $C$ Model & D Model \\
\hline \multirow{2}{*}{$Q$} & $(a-c)\left(2 k \beta-\gamma^{2}\right)$ & $(a-c)\left(2 k \beta-\gamma^{2}\right)$ & $(a-c) k \beta^{2}$ & $(a-c) k \beta^{2}$ \\
\hline & $\overline{2\left(2 k \beta-\gamma^{2}\right)(1-\mu)-k}$ & $\overline{4\left(2 \beta k-\gamma^{2}\right)(1-\mu)-k}$ & $\overline{2 k \beta^{2}(1-\mu)-\gamma^{2}}$ & $\overline{4 \beta^{2} k(1-\mu)-\gamma^{2}}$ \\
\hline \multirow{2}{*}{$Q_{s}$} & $(a-c) k \beta$ & $(a-c) k \beta$ & $(a-c) k \beta^{2}$ & $(a-c) k \beta^{2}$ \\
\hline & $2\left(2 k \beta-\gamma^{2}\right)(1-\mu)-k$ & $4\left(2 \beta k-\gamma^{2}\right)(1-\mu)-k$ & $2 k \beta^{2}(1-\mu)-\gamma^{2}$ & $4 \beta^{2} k(1-\mu)-\gamma^{2}$ \\
\hline \multirow{2}{*}{$p$} & $(a+c)\left(2 k \beta-\gamma^{2}\right)(1-\mu)-a k$ & $(3 a+c)\left(2 \beta k-\gamma^{2}\right)(1-\mu)-a k$ & $(a+c) k \beta^{2}(1-\mu)-a \gamma^{2}$ & $(3 a+c) \beta^{2} k(1-\mu)-a \gamma^{2}$ \\
\hline & $2\left(2 k \beta-\gamma^{2}\right)(1-\mu)-k$ & $4\left(2 \beta k-\gamma^{2}\right)(1-\mu)-k$ & $2 k \beta^{2}(1-\mu)-\gamma^{2}$ & $4 \beta^{2} k(1-\mu)-\gamma^{2}$ \\
\hline \multirow[b]{2}{*}{$p_{s}$} & $(a-c) k$ & $(a-c) k$ & $(a-c) \gamma^{2}$ & $(a-c) \gamma^{2}$ \\
\hline & $\overline{2\left(2 k \beta-\gamma^{2}\right)(1-\mu)-k}$ & $\overline{4\left(2 \beta k-\gamma^{2}\right)(1-\mu)-k}$ & $\overline{2 k \beta^{2}(1-\mu)-\gamma^{2}}$ & $\overline{4 \beta^{2} k(1-\mu)-\gamma^{2}}$ \\
\hline & $(a-c) \gamma$ & $(a-c) \gamma$ & $(a-c) \beta \gamma$ & $(a-c) \beta \gamma$ \\
\hline$q_{s}$ & $2\left(2 k \beta-\gamma^{2}\right)(1-\mu)-k$ & $\overline{4\left(2 \beta k-\gamma^{2}\right)(1-\mu)-k}$ & $\overline{2 k \beta^{2}(1-\mu)-\gamma^{2}}$ & $\overline{4 \beta^{2} k(1-\mu)-\gamma^{2}}$ \\
\hline \multirow{2}{*}{$\pi_{r}$} & & $(a-c)^{2}\left(2 k \beta-\gamma^{2}\right)$ & & $(a-c)^{2} k \beta^{2}$ \\
\hline & & $2\left[4\left(2 \beta k-\gamma^{2}\right)(1-\mu)-k\right]$ & & $2\left[4 \beta^{2} k(1-\mu)-\gamma^{2}\right]$ \\
\hline \multirow[b]{2}{*}{$\pi_{m}$} & & $(a-c)^{2}\left(2 \beta k-\gamma^{2}\right)^{2}(1-\mu)$ & & $(a-c)^{2} k^{2} \beta^{4}(1-\mu)$ \\
\hline & & $\frac{\left[4\left(2 \beta k-\gamma^{2}\right)(1-\mu)-k\right]^{2}}{2}$ & & {$\left[4 \beta^{2} k(1-\mu)-\gamma^{2}\right]^{2}$} \\
\hline \multirow{2}{*}{$\pi_{s c}$} & $(a-c)^{2}\left(2 k \beta-\gamma^{2}\right)$ & $(a-c)^{2}\left(2 k \beta-\gamma^{2}\right)\left(6\left(2 k \beta-\gamma^{2}\right)(1-\mu)-k\right)$ & $(a-c)^{2} k \beta^{2}$ & $(a-c)^{2} k \beta^{2}\left[6 k \beta^{4}(1-\mu)-\gamma^{2}\right]$ \\
\hline & $2\left[2\left(2 k \beta-\gamma^{2}\right)(1-\mu)-k\right]$ & $2\left(4\left(2 k \beta-\gamma^{2}\right)(1-\mu)-k\right)^{2}$ & $2\left[2 k \beta^{2}(1-\mu)-\gamma^{2}\right]$ & $2\left[4 \beta^{2} k(1-\mu)-\gamma^{2}\right]^{2}$ \\
\hline
\end{tabular}

Table 1. Equilibrium values summary sheet. 
According to backward induction, we order $p=w+g$. The manufacturer's wholesale price can be obtained as follows:

$$
w(p)=a+c-p
$$

We put Equation (5) into Equation (4) and construct Lagrange function about retailer's profit:

$$
L_{r}^{D}=[p-(a+c-p)]\left(\frac{a-p}{1-\mu}\right)+p_{s}\left(\frac{a-p}{1-\mu}-\beta p_{s}+\gamma q_{s}\right)-\frac{1}{2} k q_{s}^{2}+\lambda\left(\beta p_{s}-\gamma q_{s}\right)
$$

Retailer's optimal strategy has to meet the following:

$$
\frac{\partial L_{r}^{D}}{\partial p}=0 ; \frac{\partial L_{r}^{D}}{\partial p_{s}}=0 ; \frac{\partial L_{r}^{D}}{\partial q_{s}}=0 ; \lambda\left(\beta p_{s}-\gamma q_{s}\right)=0 ; \lambda \geq 0 ; \beta p_{s} \geq \gamma q_{s}
$$

(1) When $\lambda=0, \beta p_{s}>\gamma q_{s}$, that's part of extended warranty. By satisfying condition (I) we can obtain retailer's corresponding equilibrium strategy:

$$
p^{D}=\frac{(3 a+c)\left(2 \beta k-\gamma^{2}\right)(1-\mu)-a k}{4\left(2 \beta k-\gamma^{2}\right)(1-\mu)-k} ; p_{s}^{D}=\frac{(a-c) k}{4\left(2 \beta k-\gamma^{2}\right)(1-\mu)-k} ; \quad q_{s}^{D}=\frac{(a-c) \gamma}{4\left(2 \beta k-\gamma^{2}\right)(1-\mu)-k}
$$

Then by putting $p^{D}$ into Equation (3), we can obtain manufacturer's wholesale price of the commodity under the optimal decision:

$$
w^{D}=\frac{(a+3 c)\left(2 \beta k-\gamma^{2}\right)(1-\mu)-c k}{4\left(2 \beta k-\gamma^{2}\right)(1-\mu)-k}
$$

(2) When $\lambda \neq 0, \beta p_{s}=\gamma q_{s}$, that's all of extended warranty. Being similar to the analysis method of the first part (1), by satisfying condition (II) we can obtain the corresponding optimal decision:

$$
\begin{aligned}
& p^{D}=\frac{(3 a+c) \beta^{2} k(1-\mu)-a \gamma^{2}}{4 \beta^{2} k(1-\mu)-\gamma^{2}} ; p_{s}^{D}=\frac{(a-c) \gamma^{2}}{4 \beta^{2} k(1-\mu)-\gamma^{2}}, \\
& q_{s}^{D}=\frac{(a-c) \beta \gamma}{4 \beta^{2} k(1-\mu)-\gamma^{2}} ; w^{D}=\frac{(3 c+a) \beta^{2} k(1-\mu)-c \gamma^{2}}{4 \beta^{2} k(1-\mu)-\gamma^{2}}
\end{aligned}
$$

Furthermore, as we have shown in Table 1, we can obtain the values of sales of commodity, the sales of extended warranty, profits of node enterprises and total profit of the system.

\section{Equilibrium Analysis}

In this section, based on the contents of Table 1, we will compare the differences of the equilibrium values of the supply chain with the extended warranty under centralized decision-making model and decentralized decision-making model and emphatically analyze the affection of network externality on the equilibrium results and differences of equilibriums.

Conclusion 1: Whether all consumers purchase extended warranty or not, in the situation of centralized decision-making model and decentralized decision-making model, all the followings are established: extended warranty price $p_{s}$, extended warranty quality $q_{s}$, commodity sales $Q$ and extended warranty sales $Q_{s}$ have positive correlations with the intensity of network externality $\mu$ while commodity retail price $p$ have negative correlation with $\mu$.

Demonstration: In the case of centralized decision-making model, when part of consumers buy extended warranty, which is $\gamma^{2}<k \beta, 0<\mu<1-\frac{k}{2 k \beta-\gamma^{2}}$. It's easy to judge the following equations:

$$
\frac{\mathrm{d}\left(p_{s}^{C}\right)}{\mathrm{d} \mu}=\frac{2 k(a-c)\left(2 k \beta-\gamma^{2}\right)}{\left[2\left(2 k \beta-\gamma^{2}\right)(1-\mu)-k\right]^{2}}>0, \frac{\mathrm{d}\left(q_{s}^{C}\right)}{\mathrm{d} \mu}=\frac{2 \gamma(a-c)\left(2 k \beta-\gamma^{2}\right)}{\left[2\left(2 k \beta-\gamma^{2}\right)(1-\mu)-k\right]^{2}}>0
$$




$$
\begin{gathered}
\frac{\mathrm{d}\left(Q^{C}\right)}{\mathrm{d} \mu}=\frac{2(a-c)\left(2 k \beta-\gamma^{2}\right)^{2}}{\left[2\left(2 k \beta-\gamma^{2}\right)(1-\mu)-k\right]^{2}}>0, \frac{\mathrm{d}\left(Q_{s}^{C}\right)}{\mathrm{d} \mu}=\frac{2 k \beta(a-c)\left(2 k \beta-\gamma^{2}\right)}{\left[2\left(2 k \beta-\gamma^{2}\right)(1-\mu)-k\right]^{2}}>0 \\
\frac{\mathrm{d}\left(p^{C}\right)}{\mathrm{d} \mu}=-\frac{k(a-c)\left(2 k \beta-\gamma^{2}\right)}{\left[2\left(2 k \beta-\gamma^{2}\right)(1-\mu)-k\right]^{2}}<0
\end{gathered}
$$

The same theory proves that it's true when all consumers buy extended warranty. In the case of decentralized decision-making model, that conclusion is also true.

Conclusion 2: Whether all consumers purchase extended warranty or not, all the followings are established: $p^{D}>p^{C}, p_{s}^{D}<p_{s}^{C}, q_{s}^{D}<q_{s}^{C}$. Specially, the value of their differences is related to the intensity of network externality $\mu$.

Demonstration: We take the situation of part of consumers buying extended warranty as an example, we order

$$
\begin{aligned}
& U_{p}=p^{D}-p^{C}=\frac{2(a-c)\left(2 k \beta-\gamma^{2}\right)^{2}(1-\mu)^{2}}{\left[2\left(2 k \beta-\gamma^{2}\right)(1-\mu)-k\right]\left[4\left(2 \beta k-\gamma^{2}\right)(1-\mu)-k\right]}, \\
& U_{p_{s}}=p_{s}^{C}-p_{s}^{D}=\frac{2(a-c) k\left(2 k \beta-\gamma^{2}\right)(1-\mu)}{\left[4\left(2 \beta k-\gamma^{2}\right)(1-\mu)-k\right]\left[2\left(2 k \beta-\gamma^{2}\right)(1-\mu)-k\right]}, \\
& U_{q_{s}}=q_{s}^{C}-q_{s}^{D}=\frac{2(a-c) \gamma\left(2 k \beta-\gamma^{2}\right)(1-\mu)}{\left[4\left(2 \beta k-\gamma^{2}\right)(1-\mu)-k\right]\left[2\left(2 k \beta-\gamma^{2}\right)(1-\mu)-k\right]},
\end{aligned}
$$

and we can obtain

$$
\begin{aligned}
& \frac{\mathrm{d}\left(U_{p}\right)}{\mathrm{d} \mu}=\frac{4(a-c) k\left(2 k \beta-\gamma^{2}\right)^{2}\left(3\left(2 k \beta-\gamma^{2}\right)(1-\mu)-k\right)(1-\mu)}{\left(2\left(2 k \beta-\gamma^{2}\right)(1-\mu)-k\right)^{2}\left(4\left(2 \beta k-\gamma^{2}\right)(1-\mu)-k\right)^{2}}, \\
& \frac{\mathrm{d}\left(U_{p_{s}}\right)}{\mathrm{d} \mu}=\frac{2(a-c) k\left(2 k \beta-\gamma^{2}\right)\left(8\left(2 k \beta-\gamma^{2}\right)^{2}(1-\mu)^{2}-k^{2}\right)}{\left(2\left(2 k \beta-\gamma^{2}\right)(1-\mu)-k\right)^{2}\left(4\left(2 \beta k-\gamma^{2}\right)(1-\mu)-k\right)^{2}}, \\
& \frac{\mathrm{d}\left(U_{a_{s}}\right)}{\mathrm{d} \mu}=\frac{2(a-c) \gamma\left(2 k \beta-\gamma^{2}\right)\left(8\left(2 k \beta-\gamma^{2}\right)^{2}(1-\mu)^{2}-k^{2}\right)}{\left(2\left(2 k \beta-\gamma^{2}\right)(1-\mu)-k\right)^{2}\left(4\left(2 \beta k-\gamma^{2}\right)(1-\mu)-k\right)^{2}}
\end{aligned}
$$

Because of $\gamma^{2}<k \beta$ and $0<\mu<1-\frac{k}{2 k \beta-\gamma^{2}}$, it's easy to judge that $U_{p}>0, U_{p_{s}}<0, U_{q_{s}}<0$, $\frac{\mathrm{d}\left(U_{p}\right)}{\mathrm{d} \mu}>0, \frac{\mathrm{d}\left(U_{p_{\mathrm{s}}}\right)}{\mathrm{d} \mu}<0$ and $\frac{\mathrm{d}\left(U_{q_{\mathrm{s}}}\right)}{\mathrm{d} \mu}<0$, then the conclusion above is proved. In the same way, it's true when all consumers buy extended warranty.

Conclusion 3: Whether all consumers purchase extended warranty or not, profits of node enterprises and supply chain system are related to the intensity of network externality $\mu$.

Demonstration: We take the situation of part of consumers buying extended warranty for example, when $\gamma^{2}<k \beta, 0<\mu<1-\frac{k}{2 k \beta-\gamma^{2}}$, then we can obtain $\frac{\mathrm{d}\left(\pi_{r}^{D}\right)}{\mathrm{d} \mu}=\frac{(a-c)^{2} k^{3} \beta^{4}}{2\left(4\left(2 k \beta-\gamma^{2}\right)(1-\mu)-k\right)^{2}}>0$, 
$\frac{\mathrm{d}\left(\pi_{m}^{D}\right)}{\mathrm{d} \mu}=\frac{(a-c)^{2} k\left(2 k \beta-\gamma^{2}\right)^{2}}{\left(4\left(2 k \beta-\gamma^{2}\right)(1-\mu)-k\right)^{2}}>0, \frac{\mathrm{d}\left(\pi_{s c}^{D}\right)}{\mathrm{d} \mu}=\frac{(a-c)^{2}\left(k^{2} \beta^{4}+\left(2 k \beta-\gamma^{2}\right)^{2}\right)\left(k+4\left(2 k \beta-\gamma^{2}\right)(1-\mu)\right)}{2\left(4\left(2 k \beta-\gamma^{2}\right)(1-\mu)-k\right)^{3}}>0$, $\frac{\mathrm{d}\left(\pi_{s c}^{C}\right)}{\mathrm{d} \mu}=\frac{(a-c)^{2}\left(2 k \beta-\gamma^{2}\right)^{2}}{\left[2\left(2 k \beta-\gamma^{2}\right)(1-\mu)-k\right]^{2}}>0$. In the same way, it's true when all consumers buy extended warranty.

Conclusion 4: Whether all consumers purchase extended warranty or not, under the influence of double-marginalization, supply chain system profit of the decentralized decision-making model is always less than the optimal system profit under centralized decision-making model. Specially, their difference is related to the intensity of network externality $\mu$.

Demonstration: We take the situation of part of consumers buying extended warranty for example, we order

$$
\begin{aligned}
& \pi_{s c}^{L}=\pi_{s c}^{C}-\pi_{s c}^{D}=\frac{2(a-c)^{2}\left(2 k \beta-\gamma^{2}\right)^{3}(1-\mu)^{2}}{\left(4\left(2 k \beta-\gamma^{2}\right)(1-\mu)-k\right)^{2}\left(2\left(2 k \beta-\gamma^{2}\right)(1-\mu)-k\right)}, \\
& \frac{\mathrm{d}\left(\pi_{s c}^{L}\right)}{\mathrm{d} \mu}=\frac{4(a-c)^{2}\left(2 k \beta-\gamma^{2}\right)^{3}(1-\mu)\left(k\left(\left(2 k \beta-\gamma^{2}\right)(1-\mu)-k\right)+(1-\mu)^{2}\left(16 k \beta\left(k \beta-\gamma^{2}\right)+4 \gamma^{4}\right)\right)}{\left(4\left(2 k \beta-\gamma^{2}\right)(1-\mu)-k\right)^{3}\left(2\left(2 k \beta-\gamma^{2}\right)(1-\mu)-k\right)^{2}},
\end{aligned}
$$

because of $\gamma^{2}<k \beta$ and $0<\mu<1-\frac{k}{2 k \beta-\gamma^{2}}$, it's easy to judge that $\pi_{s c}^{L}>0, \frac{\mathrm{d}\left(\pi_{s c}^{L}\right)}{\mathrm{d} \mu}>0$, then the conclusion is proved. In the same way, it's true when all consumers buy extended warranty.

The conclusions 1 and 3 show that simply from the perspective of the node enterprises, network externality increases the profits of the node enterprises, which plays a positive and active role. However, from the perspective of supply chain operation, conclusions 2 and 4 show that comparing with the situation of centralized decision-making model, network externality increases the efficiency loss of decentralized decision-making and widens the gap of supply chain total profits of centralized decision-making and decentralized decision-making.

\section{Two-Part Tariff (Model SP)}

From the previous section we know that network externality increases the efficiency loss of supply chain decision-makings. In this section, we attempt to use two-part tariff to coordinate the supply chain system with extended warranty.

Because of retailer's leading role, we assume that as a principal the retailer hands over products to manufacturer for manufacturing what they need and provides a contract $\left(p^{S P}, T\right)$ to manufacturer. It means that the retailer gets a fixed fee $T$ (such as slotting allowances and fees) from manufacturer by setting a lower retail price. After that, the manufacturer will decide whether to accept the contract and specifically make optimal decisions. The above ideas can be modeled as follows:

$$
\begin{gathered}
\max _{p^{S P}, p_{s}^{S P}, q_{s}^{S P}} \pi_{r}^{S P}=\left(p-w^{S P}\right) Q+p_{s} Q_{s}-\frac{1}{2} k q_{s}^{2}+T \\
\text { s.t } \beta p_{s} \geq \gamma q_{s} \\
w^{S P} \in \arg \max \pi_{m}^{S P}=\left(w^{S P}-c\right) Q-T \\
\left(w^{S P}-c\right) Q-T \geq \pi_{m}^{D R^{*}}\left(w^{S P}-c\right) Q-T \geq \pi_{m}^{D R^{*}}
\end{gathered}
$$

In the above model, Equation (7) is manufacturer's incentive compatibility conditions and Equation (8) is manufacturer's individual rationality constraint (participation constraint) conditions. Among them, $\pi_{m}^{D R^{*}}$ is manufacturer's optimal profit under decentralized decision-making model.

Similar to the method above, we can get the equilibrium values of two-part tariff model, as shown in Table 2.

Conclusion 6 Whether all consumers purchase extended warranty or not, all of the followings are established: 
Table 2. Equilibrium values of two-part tariff model.

\begin{tabular}{|c|c|c|}
\hline & Part of extended warranty & All of extended warranty \\
\hline$w^{S P}$ & $\frac{(a+c)\left(2 k \beta-\gamma^{2}\right)(1-\mu)-c k}{2\left(2 k \beta-\gamma^{2}\right)(1-\mu)-k}$ & $\frac{(a+c) k \beta^{2}(1-\mu)-c \gamma^{2}}{2 k \beta^{2}(1-\mu)-\gamma^{2}}$ \\
\hline$p^{S P}$ & $\frac{(a+c)\left(2 k \beta-\gamma^{2}\right)(1-\mu)-a k}{2\left(2 k \beta-\gamma^{2}\right)(1-\mu)-k}$ & $\frac{(a+c) k \beta^{2}(1-\mu)-a \gamma^{2}}{2 k \beta^{2}(1-\mu)-\gamma^{2}}$ \\
\hline$p_{s}^{S P}$ & $\frac{(a-c) k}{2\left(2 k \beta-\gamma^{2}\right)(1-\mu)-k}$ & $\frac{(a-c) \gamma^{2}}{2 k \beta^{2}(1-\mu)-\gamma^{2}}$ \\
\hline$q_{s}^{S P}$ & $\frac{(a-c) \gamma}{2\left(2 k \beta-\gamma^{2}\right)(1-\mu)-k}$ & $\frac{(a-c) \beta \gamma}{2 k \beta^{2}(1-\mu)-\gamma^{2}}$ \\
\hline$Q^{S P}$ & $\frac{(a-c)\left(2 k \beta-\gamma^{2}\right)}{2\left(2 k \beta-\gamma^{2}\right)(1-\mu)-k}$ & $\frac{(a-c) k \beta^{2}}{2 k \beta^{2}(1-\mu)-\gamma^{2}}$ \\
\hline$Q_{s}^{S P}$ & $\frac{(a-c) k \beta}{2\left(2 k \beta-\gamma^{2}\right)(1-\mu)-k}$ & $\frac{(a-c) k \beta^{2}}{2 k \beta^{2}(1-\mu)-\gamma^{2}}$ \\
\hline$\pi_{m}^{S P}$ & $\frac{(a-c)^{2}\left(2 k \beta-\gamma^{2}\right)^{2}(1-\mu)}{\left(4\left(2 k \beta-\gamma^{2}\right)(1-\mu)-k\right)^{2}}$ & $\frac{(a-c)^{2} k^{2} \beta^{4}(1-\mu)}{\left(4 k \beta^{2}(1-\mu)-\gamma^{2}\right)^{2}}$ \\
\hline$\pi_{r}^{S P}$ & $\frac{(a-c)^{2}\left(2 k \beta-\gamma^{2}\right)\left(6\left(2 k \beta-\gamma^{2}\right)(1-\mu)\left(2\left(2 k \beta-\gamma^{2}\right)(1-\mu)-k\right)+k^{2}\right)}{2\left(2\left(2 k \beta-\gamma^{2}\right)(1-\mu)-k\right)\left(4\left(2 k \beta-\gamma^{2}\right)(1-\mu)-k\right)^{2}}$ & $\frac{(a-c)^{2} k \beta^{2}\left(6 k \beta^{2}(1-\mu)\left(2 k \beta^{2}(1-\mu)-\gamma^{2}\right)+\gamma^{4}\right)}{2\left(2 k \beta^{2}(1-\mu)-\gamma^{2}\right)\left(4 k \beta^{2}(1-\mu)-\gamma^{2}\right)^{2}}$ \\
\hline$\pi_{s c}^{S P}$ & $\frac{(a-c)^{2}\left(2 k \beta-\gamma^{2}\right)}{2\left(2\left(2 k \beta-\gamma^{2}\right)(1-\mu)-k\right)}$ & $\frac{(a-c)^{2} k \beta^{2}}{2\left(2 k \beta^{2}(1-\mu)-\gamma^{2}\right)}$ \\
\hline
\end{tabular}

$p^{S P}=p^{C}, \quad p_{s}^{S P}=p_{s}^{C}, \quad q_{s}^{S P}=q_{s}^{C}, \pi_{s c}^{S P}=\pi_{s c}^{C}, \pi_{r}^{D}<\pi_{r}^{S P}, \pi_{m}^{D}=\pi_{m}^{S P}$.

Demonstration: The equal equilibrium values can be seen directly. We take retailer's profit $\pi_{r}$ under the situation of part of consumers buying extended warranty for example, by $\gamma^{2}<k \beta$ and $0<\mu<1-\frac{k}{2 k \beta-\gamma^{2}}$, we can obtain $U_{1}=\pi_{r}^{S P}-\pi_{r}^{D}=\frac{2(a-c)^{2}\left(2 k \beta-\gamma^{2}\right)^{3}(1-\mu)^{2}}{\left(2\left(2 k \beta-\gamma^{2}\right)(1-\mu)-k\right)\left(4\left(2 k \beta-\gamma^{2}\right)(1-\mu)-k\right)^{2}}>0$. It's true when all consumers buy extended warranty.

Conclusion 6 states that two-part tariff can optimize the decision-making efficiency of supply chain system and obtain the supply chain system Pareto improvement and can also achieve the perfect coordination of supply chain $\left(\pi_{s c}^{S P}=\pi_{s c}^{C}\right)$. But in that situation, the manufacturer only obtains retained profit and retailer grabs super profit.

\section{Analysis of Example}

Next, we further analyze the above conclusions by an example. Without loss of generality, we assume that $a=1000, c=100, \beta=4, \gamma=2$ and (1) when part of consumers buy extended warranty, according to condition (I) we assume $k=12 / 10,0<\mu<11 / 14$; (2) when all of consumers buy extended warranty, according to condition (II) ,we assume $k=8 / 10,0<\mu<11 / 16$. Then we respectively make comparison diagrams of prod- 
uct price, extended warranty price, extended warranty quality, commodity sales, extended warranty sales, profits of node enterprises and supply chain system under mode $C$ (centralized decision-making), model $D$ (decentralized decision-making )and model SP (two-part tariff) as follows:

(1) Comparison figures of retailer's retail price and product sales about $\mu$ under each model.

Figures 1-4 show that whether all consumers purchase extended warranty or not, the retail price and sales are influenced by network externality under $C, D$ and $S P$ model. It concretely shows: along with the augment of $\mu$, retail price decreases and commodity sales increases with the increase of the intensity of network externality $\mu$. This means that in the market environment with stronger network externality, the retailer tends to increase sales by lower the commodity price in order to expand the follow-up potential consumers of extended warranty.

(2) Comparison diagrams of retailer's extended warranty price, extended warranty quantity and extended warranty sales about $\mu$ under each model.

Figures 5-10 show that whether all consumers purchase extended warranty or not, the price, quantity and sales of extended warranty are influenced by network externality under $C, D$ and $S P$ model. It concretely shows: the price, quantity and sales of extended warranty increases with the increase of the intensity of network externality $\mu$. It shows that in the market environment of stronger network externality, the retailer will prefer extended warranty pricing strategy with higher quality and higher price. On the one hand, providing high quality extended warranty can attract more consumers to buy extended warranty. On the other hand, it will obtain higher extended warranty sales revenue by setting higher prices.

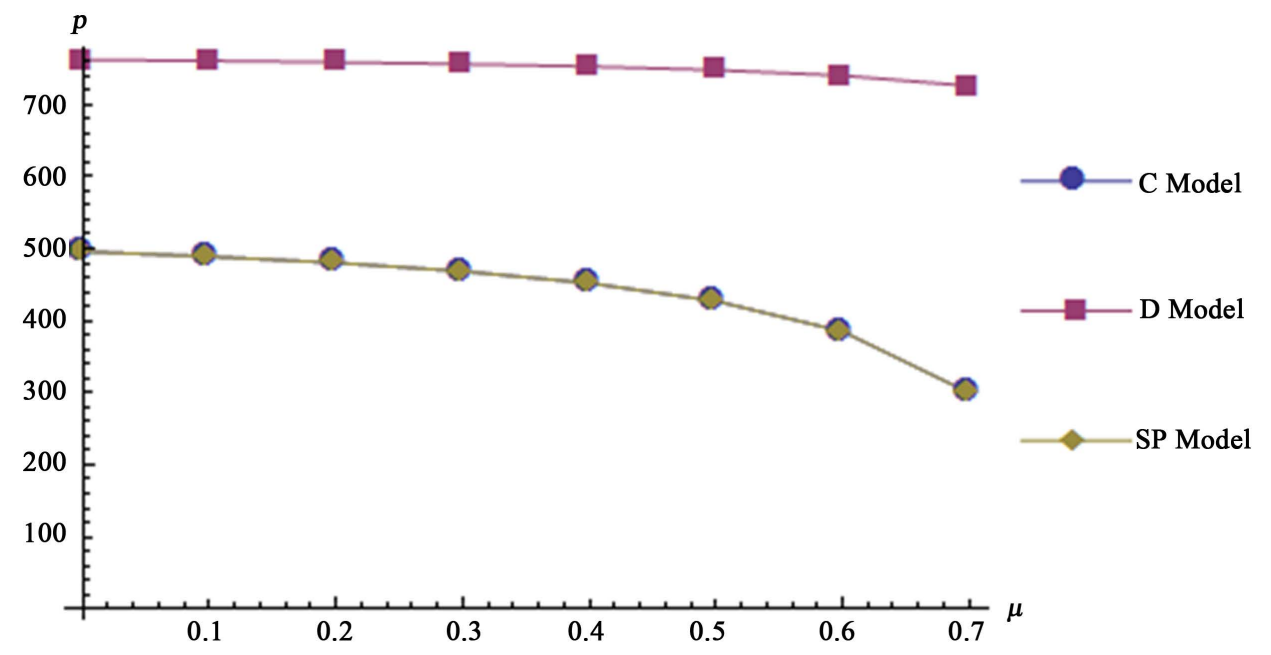

Figure 1. Comparison of retail price when part of consumers buy extended warranty and $\mu$ changes.

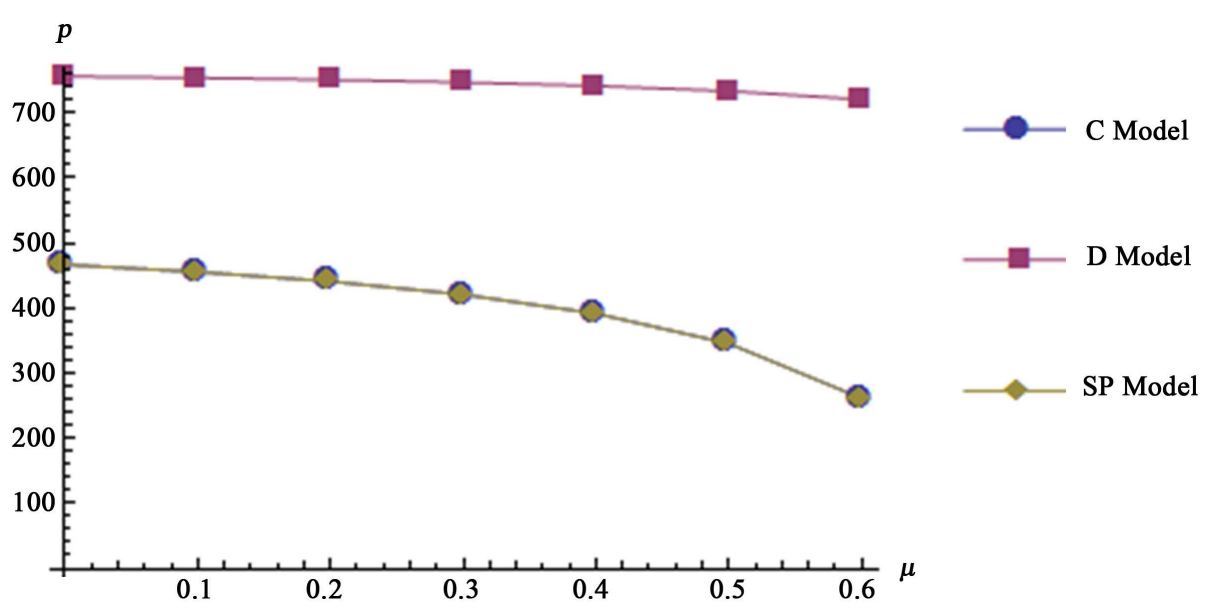

Figure 2. Comparison of retail price when all consumers buy extended warranty and $\mu$ changes. 


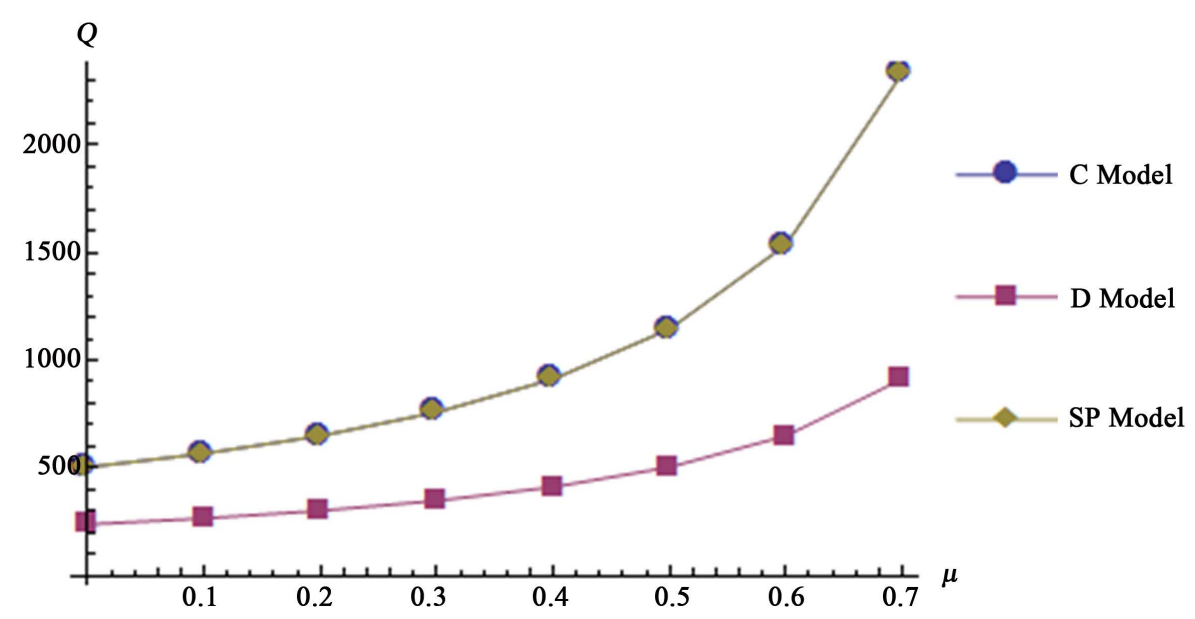

Figure 3. Comparison of product sales when part of consumers buy extended warranty and $\mu$ changes.

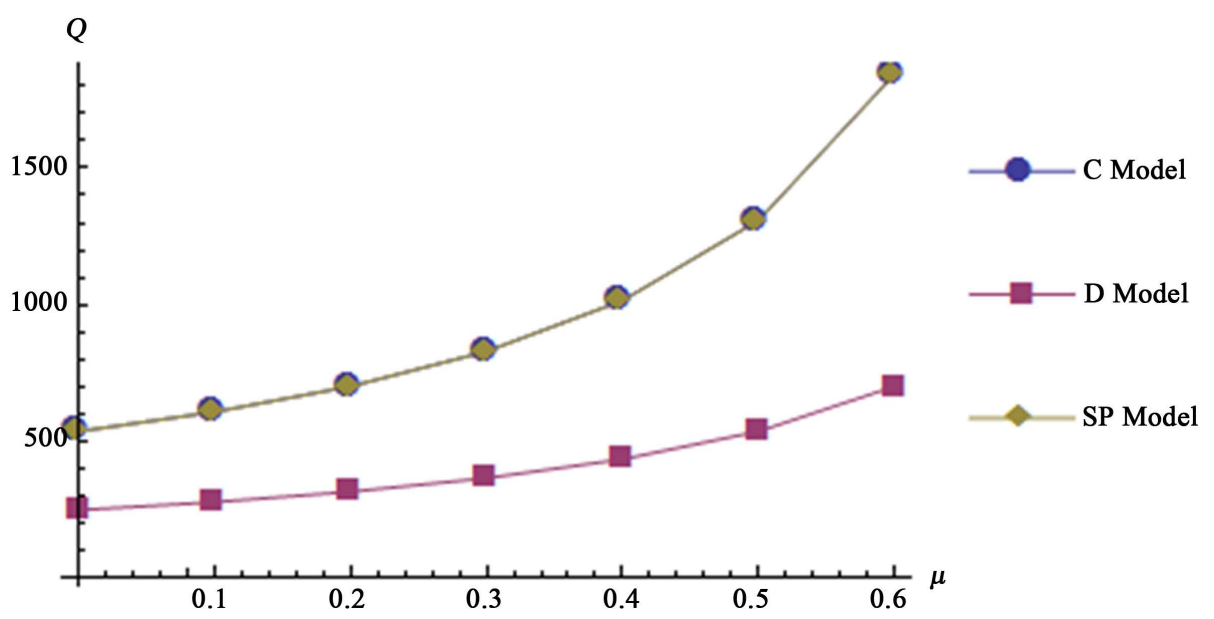

Figure 4. Comparison of product sales when all consumers buy extended warranty and $\mu$ changes.

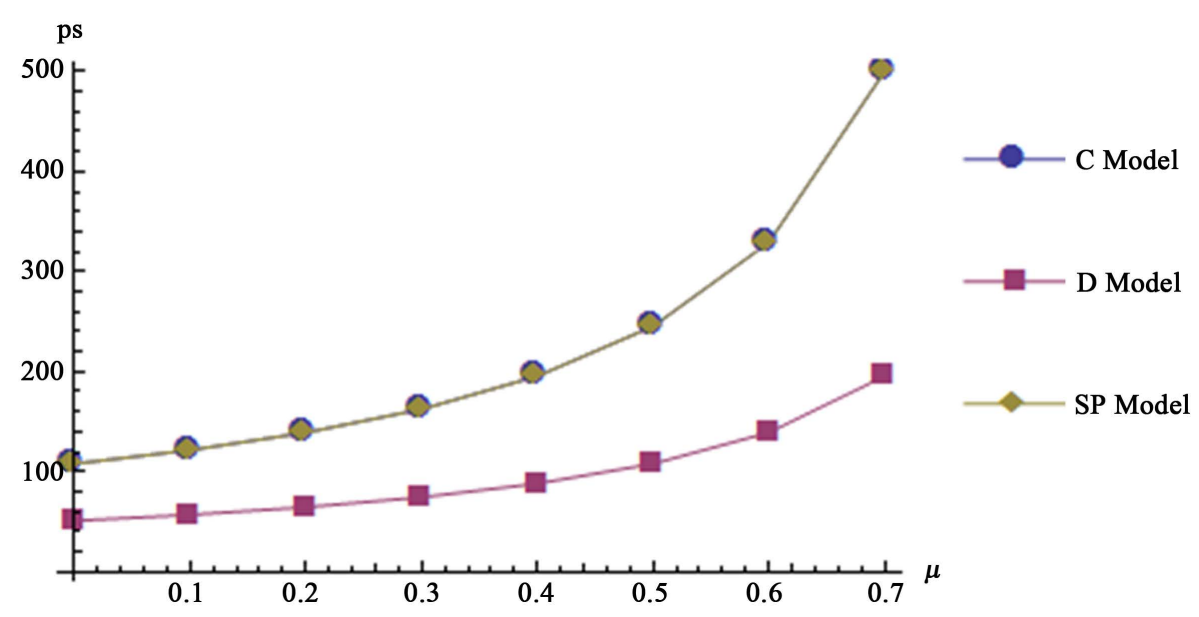

Figure 5. Comparison of extended warranty price when part of consumers buy extended warranty and $\mu$ changes. 


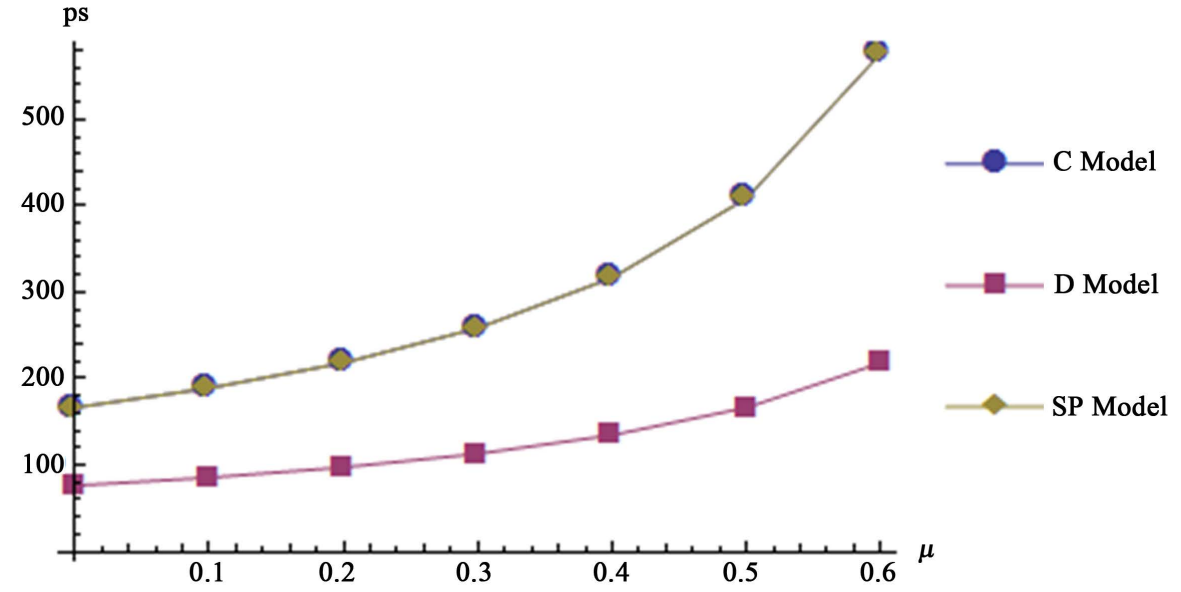

Figure 6. Comparison of extended warranty price when all consumers buy extended warranty price and $\mu$ changes.

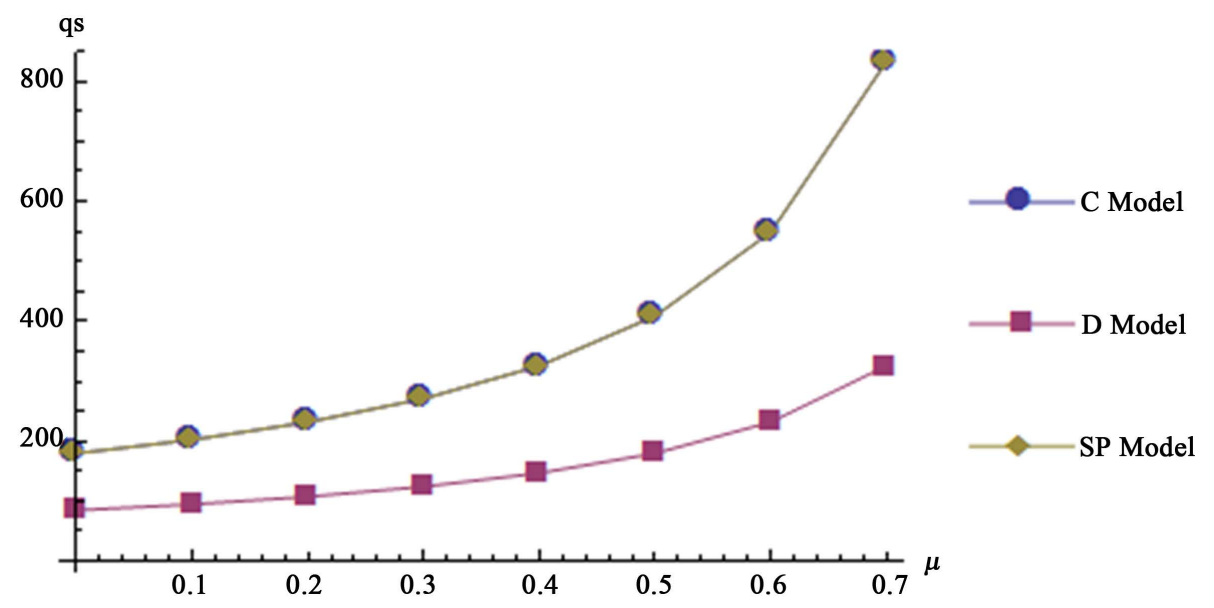

Figure 7. Comparison of extended warranty quantity when part of consumers buy extended warranty and $\mu$ changes.

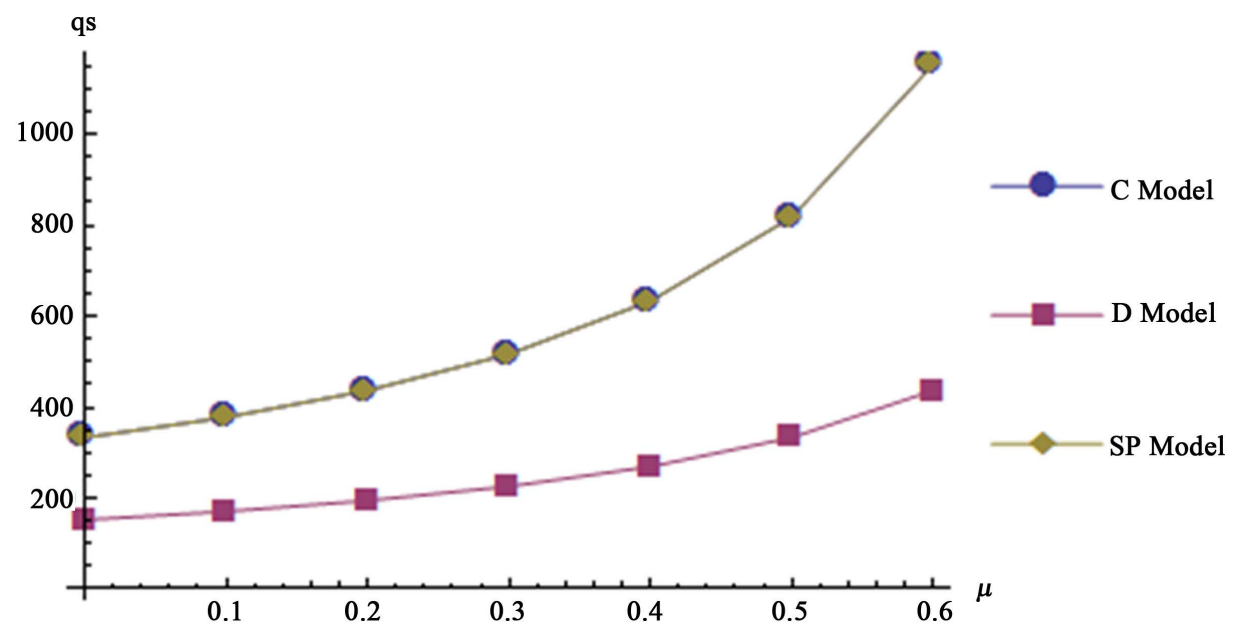

Figure 8. Comparison of extended warranty quantity when all consumers buy extended warranty quantity and $\mu$ changes. 


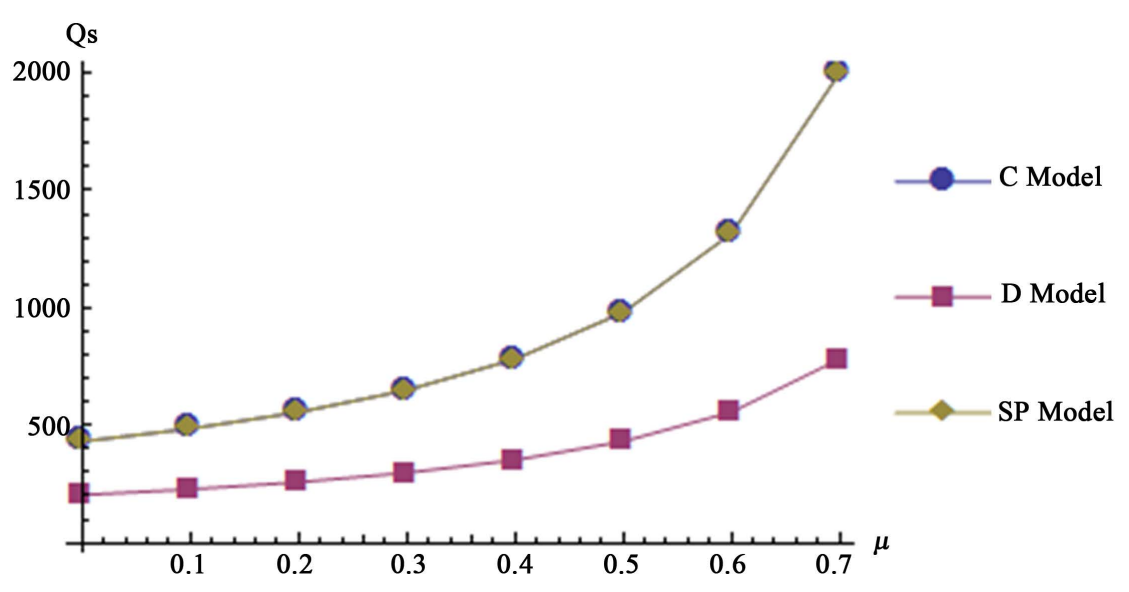

Figure 9. Comparison of extended warranty sales when part of consumers buy extended warranty and $\mu$ changes.

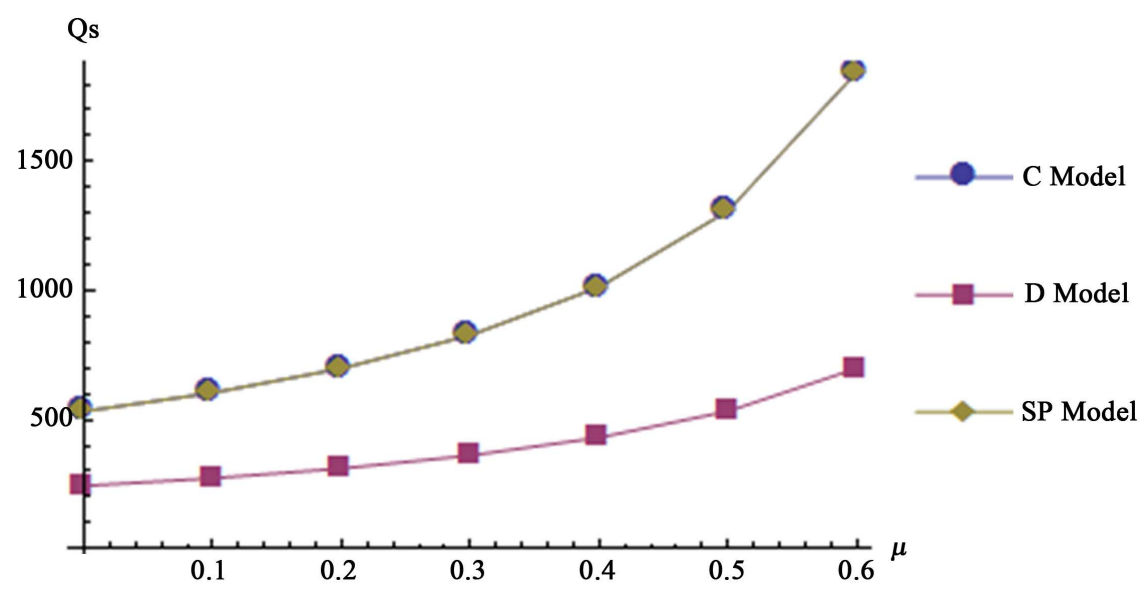

Figure 10. Comparison of extended warranty sales when all consumers buy extended warranty quantity and $\mu$ changes.

Throughout the above illustrations, by comparing $C$ model with $D$ model, we found that equilibrium values under the decentralized decision-making model deviated from the optimal values of centralized decision-making model and the differences of them increased with the increasing of the intensity of network externalities $\mu$. This showed that the decision-making efficiency of supply chain under decentralized decision-making model was inferior to the situation of centralized decision-making model and network externality intensified the efficiency loss. At the same time, by comparing $C$ model, $D$ model with $S P$ model, we found that the price, quantity and sales of extended warranty under two-part tariff were better than the equilibrium values under decentralized decision-making model and agreed with the optimal values under centralized decision-making model. That showed two-part tariff could perfectly improve the decision efficiency of supply chain node enterprises.

(3) Comparison figures of the profits of manufacturer, retailer and the supply chain about $\mu$ under each model.

Figures 11-16 showed that whether all consumers purchase extended warranty or not, profits of the manufacturer, the retailer and the supply chain system under $C, D$ and $S P$ model were influenced by network externality. It concretely showed: profits of the manufacturer, the retailer and the supply chain system increased with the increase of the intensity of network externality $\mu$. At the same time, we found that (1) Whether all consumers purchase extended warranty or not, product price, extended warranty price and quantity under the decentralized decision-making model deviated from optimal values of centralized decision-making model and the manufacturer and retailer made decisions from the point of maximizing their self-interest so that the system profit under the decentralized decision-making model was always lower than optimal values of centralized decision-making 


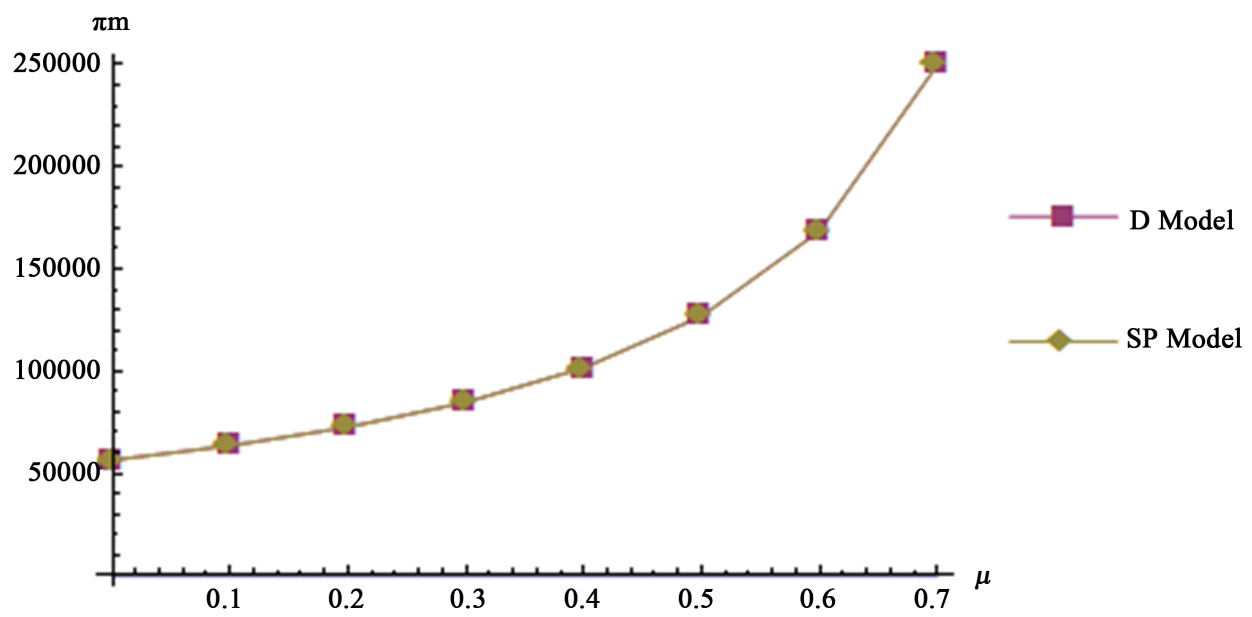

Figure 11. Comparison of manufacturer's profit when part of consumers buy extended warranty and $\mu$ changes.

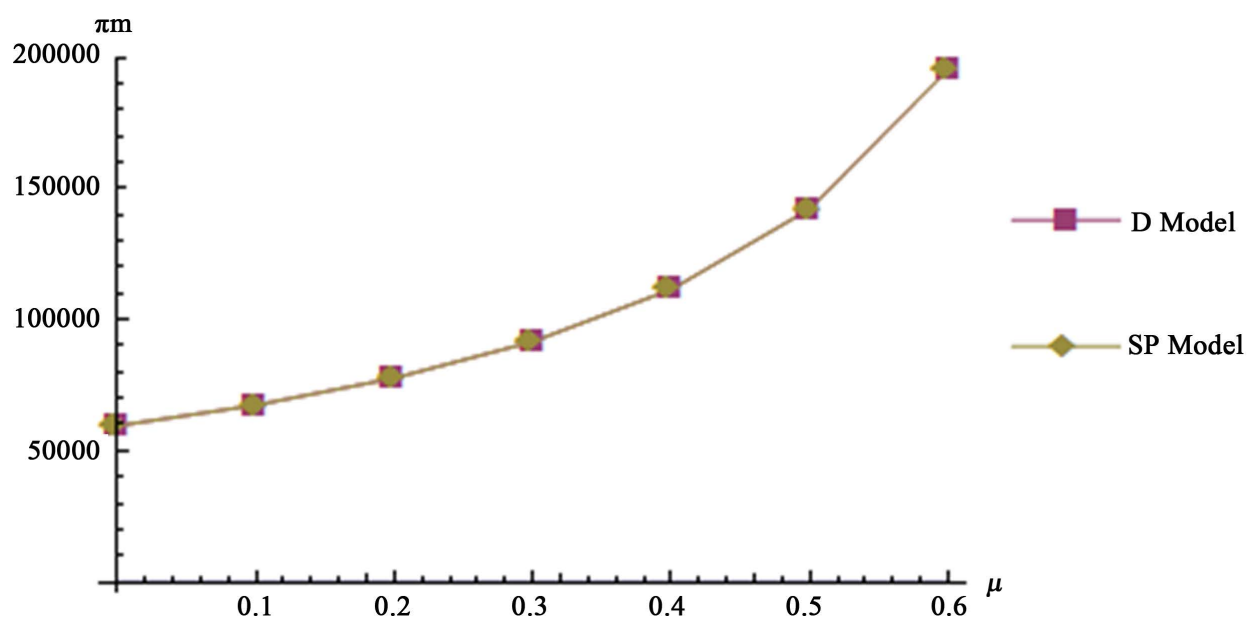

Figure 12. Comparison of manufacturer's profit when all consumers buy extended warranty quantity and $\mu$ changes.

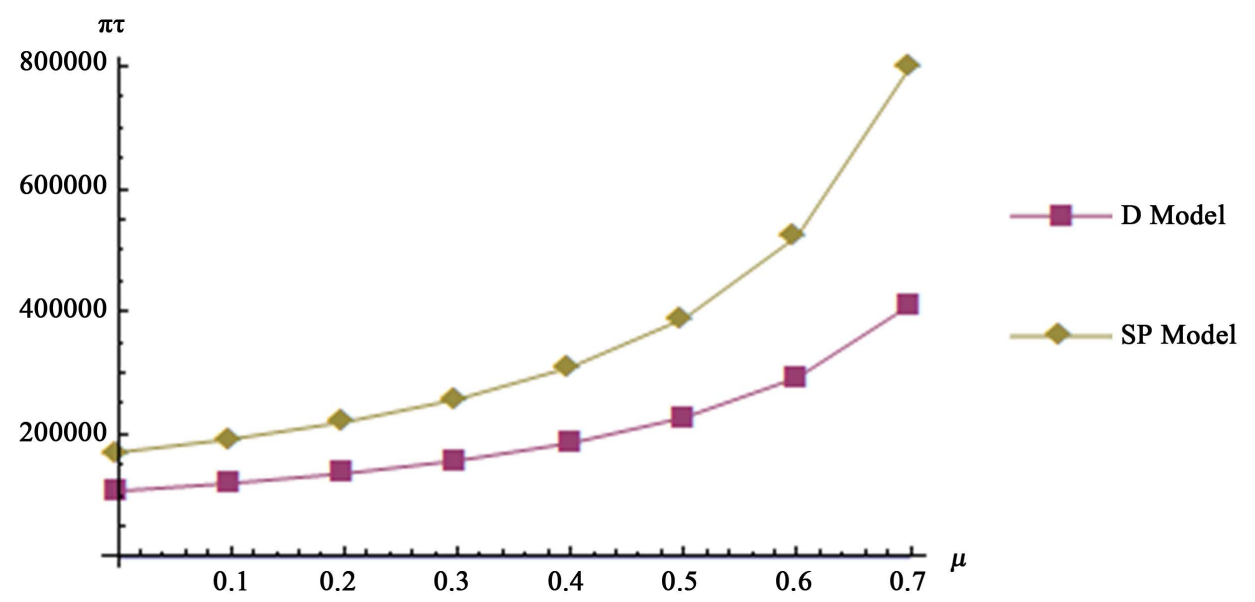

Figure 13. Comparison of retailer's profit when part of consumers buy extended warranty and $\mu$ changes. 


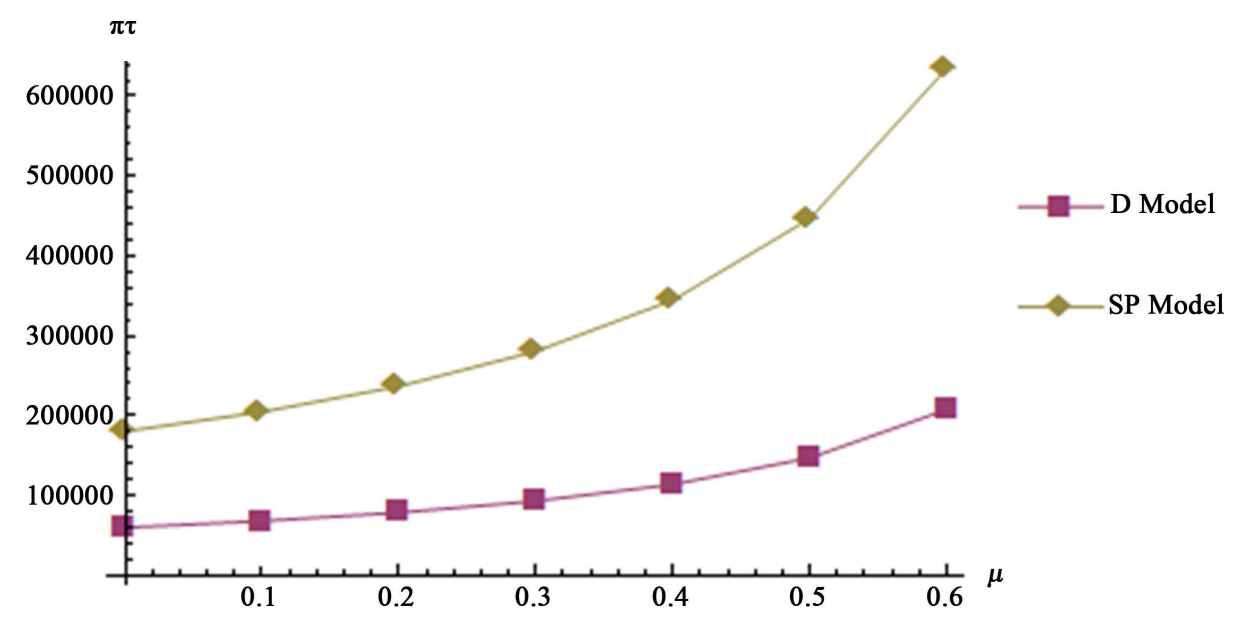

Figure 14. Comparison of retailer's profit when all consumers buy extended warranty quantity and $\mu$ changes.

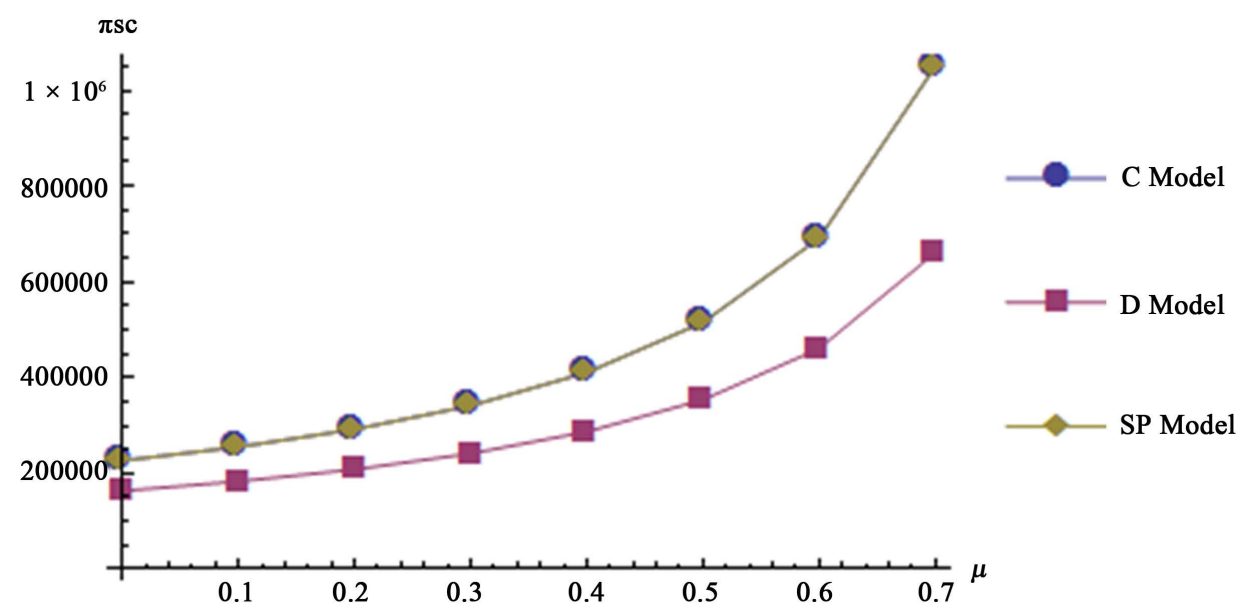

Figure 15. Comparison of profit of supply chain when part of consumers buys extended warranty and $\mu$ changes.

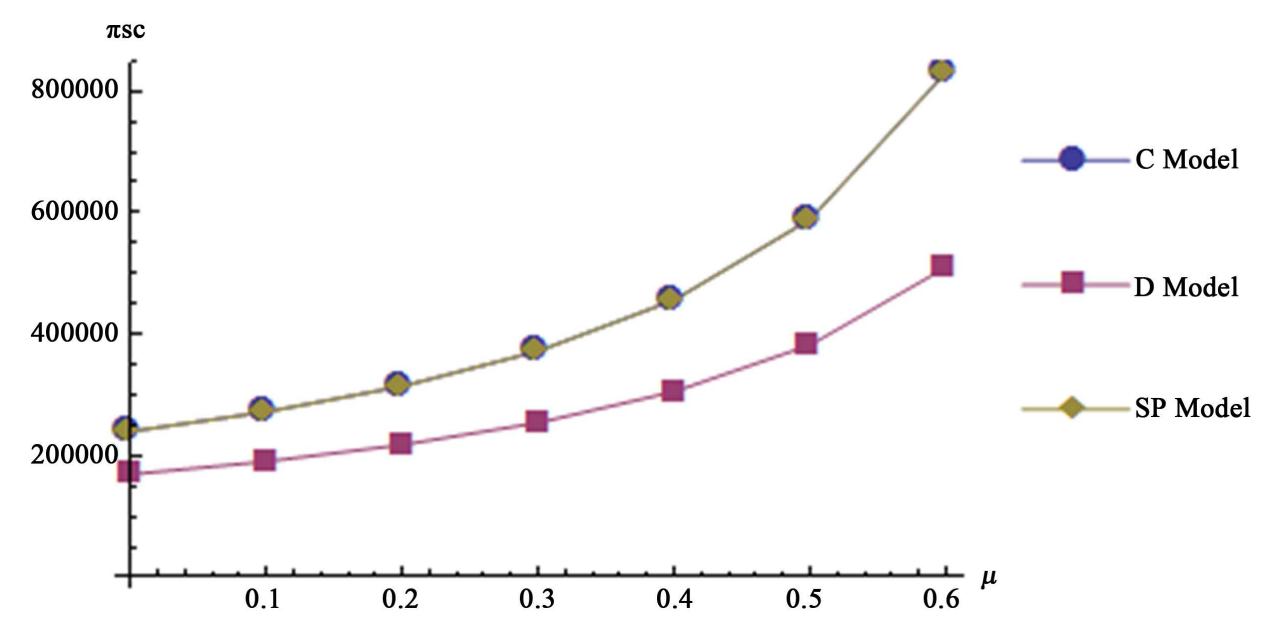

Figure 16. Comparison of profit of supply chain when all consumers buy extended warranty quantity and $\mu$ changes. 
model and the differences of them increased with the increasing of the intensity of network externality $\mu$; (2) Under two-part tariff, the supply chain system could obtain the Pareto improvement and manufacturer only obtained retained income, while retailer could obtain higher profits; (3) Two-part tariff could perfectly coordinate the supply chain system with extended warranty. The same as the optimal values of centralized decision-making model, systematic total profit under the contract was better than profit under decentralized decision-making model.

\section{Conclusions}

Under the condition of network externality, we structured a two-stage supply chain system with extended warranty and the leading retailer. Firstly, in the centralized decision-making and decentralized decision-making mode, we respectively discussed and compared commodity pricing, extended warranty pricing, service quality decision-making and system profits of the node enterprises and we analyzed the effect of network externality on each decision variables and profits. Then we tried to use the two-part tariff to coordinate the supply chain system. Finally, we further analyzed it by the example. We got the following conclusions.

(1) The intensity of network externality had an important impact on the optimal decision of two-stage supply chain system with extended warranty. The extended warranty price, the extended warranty quality, product sales, extended warranty sales, node enterprises profits and the systematic total profits were positive related to the intensity of network externality $\mu$ and commodity retail price had negative correlation with $\mu$.

(2) Network externality exacerbated the efficiency loss of decision-making.

(3) Two-part tariff could perfectly coordinate the supply chain system with extended warranty. As the optimal values in the centralized decision-making model, systematic total profit under the contract was better than profit under decentralized decision-making model. Because of retailer's dominant position and stronger bargaining power, manufacturer only obtained retained income, while retailer grabbed the excess profits.

In this paper ,there are some shortcomings, for example: (1) We only considered the situation of commodity sales affected by price and extended warranty affected by price and quality under the network externality, without considering the situation of goods and extended warranty affected by the promotional effort; (2) We only considered complete rationality of the node enterprises in supply chain with the goal of maximizing profit, without considering the situation of supply chain node enterprises affected by fairness. Those are directions which can be extended and finished later.

\section{Acknowledgements}

The study of this paper is supported by Natural Science Foundation of Guangdong Province (2014A030313391) and Key Disciplines and Projects Development Foundation for Management School, Jinan University (GY14005).

\section{References}

[1] Padmanabhan, V., Rao, R.C. (1993) Warranty Policy and Extended Service Contracts: Theory and an Application to Automobiles. Marketing Science, 12, 230-247. http://dx.doi.org/10.1287/mksc.12.3.230

[2] Padmanabhan, V. (1995) Usage Heterogeneity and Extended Warranties. Journal of Economics \& Management Strategy, 4, 33-53. http://dx.doi.org/10.1111/j.1430-9134.1995.00033.x

[3] Lam, Y. and Kwok Wai Lam, P. (2001) An Extended Warranty Policy with Options Open to Consumers. European Journal of Operational Research, 131, 514-529. http://dx.doi.org/10.1016/S0377-2217(00)00091-6

[4] Jack, N., Murthy, D.N.P. (2007) A Flexible Extended Warranty and Related Optimal Strategies. The Journal of the Operational Research Society, 58, 1612-1620. http://dx.doi.org/10.1057/palgrave.jors.2602326

[5] Hartman, J.C. and Laksana, K. (2009) Designing and Pricing Menus of Extended Warranty Contracts. Naval Research Logistics (NRL), 56, 199-214. http://dx.doi.org/10.1002/nav.20333

[6] Gallego, G., Wang, R., Ward, J., Hu, M. and Beltran, J.L. (2014) Flexible-Duration Extended Warranties with Dynamic Reliability Learning. Production and Operations Management, 23, 645-659. http://dx.doi.org/10.1111/poms.12178

[7] Li, K.P., Mallik, S. and Chhajed, D. (2012) Design of Extended Warranties in Supply Chains under Additive Demand. Production and Operations Management, 21, 730-746. http://dx.doi.org/10.1111/j.1937-5956.2011.01300.x

[8] Desai, P.S. and Padmanabhan, P. (2004) Durable Good, Extended Warranty and Channel Coordination. Review of Marketing Science, 2, 1-25. http://dx.doi.org/10.2202/1546-5616.1004 
[9] Wang, S.J. and Hu, Q.Y. (2010) Service Modes Analysis Based on extended Warranty Services Desirability Index. Computer Integrated Manufacturing System, 16, 2277-2284.

[10] Zhang, X.M., Liu, X.Y. and Fu, H.Y. (2012) Manufacturer's Sales Channel Selection for Extended Warranty Based on the Influence of Service Level. Industrial Engineering Journal, 15, 44-49.

[11] Katz, M.L. and Shapiro, C. (1985) Network Externalities, Competition, and Compatibility. The American Economic Review, 75, 424-440.

[12] Shankar, V. and Bayus, B.L. (2003) Network Effects and Competition: An Empirical Analysis of the Home Video Game Industry. Strategic Management Journal, 24, 375-384. http://dx.doi.org/10.1002/smj.296

[13] Tomak, K. and Keskin, T. (2008) Exploring the Trade-Off between Immediate Gratification and Delayed Network Externalities in the Consumption of Information Goods. European Journal of Operational Research, 187, 887-902. http://dx.doi.org/10.1016/j.ejor.2006.04.049

[14] Xu, L. and Chen, H.M. (2006) Study on Pricing Strategy Choice of Firms with Network Externality. Journal of Management Science in China, 9, 23-30.

[15] Kristiansen, E.G. (1998) R\&D in the Presence of Network Externalities: Timing and Compatibility. The RAND Journal of Economics, 29, 531-547.

[16] Li, K.K. and Chen, H.M. (2006) Analysis of Innovation Leader’s R\&D Incentives in Network Externality Industry. Journal of Systems Engineering, 21, 171-175.

[17] Chen, H. and Chen, C. (2011) Compatibility under Differentiated Duopoly with Network Externalities. Journal of Industry, Competition and Trade, 11, 43-55. http://dx.doi.org/10.1007/s10842-009-0066-1

[18] Pan, X.J., Chen, H.M. and Xu, L. (2008) Fee versus Royalty Technology Licensing with Network Externality. Journal of Management Science in China, 11, 11-17.

[19] Yi, Y.Y. and Yao, J.J. (2008) Supply Chain Coordination for Extended Warranty under Network Externality. Computer Integrated Manufacturing System, 11, 11-17. 